\title{
Increased Spironolactone in Advanced Heart Failure: Effect of Doses Greater than 25 mg/Day on Plasma Potassium Concentration
}

\author{
Dmitry Shchekochikhin ${ }^{a} \quad J o A n n ~$ Lindenfeld $^{b} \quad$ Robert Schrier $^{a}$ \\ Divisions of a Renal Diseases and Hypertension and ${ }^{b}$ Cardiology, University of Colorado School of \\ Medicine, Aurora, Colo., USA
}

\section{Key Words}

Spironolactone $\cdot$ Hyperkalemia $\cdot$ Heart failure

\begin{abstract}
Background: Daily doses of spironolactone higher than $25 \mathrm{mg}$ are rarely used in heart failure (HF) patients, presumably due to the concern for hyperkalemia. However, in advanced HF, doses $\geq 50 \mathrm{mg}$ have been found to be necessary to produce natriuresis. The aim of the present study was to examine the safety of natriuretic doses of spironolactone (50-200 mg) on serum potassium concentration in New York Heart Association (NYHA) class III/IV HF patients over several weeks. Methods: 18 patients with advanced HF received 50-200 mg of spironolactone in addition to standard treatment. Serum electrolytes, BUN and serum creatinine were assessed at baseline, during increased doses of spironolactone and at the 1-month follow-up. Results: During a total of 738 patient-weeks, there was no significant increase in mean serum potassium (4.0 vs. $4.2 \mathrm{mEq} / \mathrm{l}$ ) or serum creatinine (1.3 vs. $1.4 \mathrm{mg} / \mathrm{dl})$. However, in 3 patients, spironolactone treatment was stopped due to a mean increase in serum creatinine (1.9 vs. 2.6 $\mathrm{mg} / \mathrm{dl}$ ) and in one of them, an increase in serum potassium (4.4 vs. $5.2 \mathrm{mEq} / \mathrm{l}$ ) was noted. Conclusion: Increased doses of spironolactone are generally safe during outpatient follow-up in selected patients with advanced HF, who are receiving treatment with ACE inhibitors, betablockers, and loop diuretics.

Copyright $(2013$ S. Karger AG, Basel
\end{abstract}

\section{Introduction}

Mineralocorticoid receptor antagonists (MRA), namely spironolactone and eplerenone, have been shown to improve mortality in a wide variety of patients with heart failure (HF) [1-3]. Relatively low doses of MRA were used in these trials. In a dose ranging study prior to 
the randomized trial, the randomized aldactone evaluation study (RALES) investigators demonstrated that $25 \mathrm{mg}$ /day of spironolactone did not decrease sodium retention in these HF patients, but doses of 50-75 mg/day were natriuretic [4]. They therefore concluded that the beneficial effect of $25 \mathrm{mg}$ of spironolactone on HF survival in the RALES trial was due to blocking the non-genomic effects of aldosterone including cardiac inflammation, fibrosis and apoptosis [1]. Since the major cause of symptoms and readmission in HF patients is congestion, improving natriuresis in these patients is likely to add additional symptomatic, and possibly survival, benefits [5]. However, natriuretic doses of MRA, i.e. $\geq 25 \mathrm{mg} /$ day of spironolactone or $50 \mathrm{mg}$ of eplerenone, are generally not used in HF patients, presumably because of the fear of hyperkalemia. After the RALES publication, a retrospective observational study from Canada reported an increased number of prescriptions for spironolactone and an increased risk of hospitalizations associated with hyperkalemia [6]. In that Canadian study, however, there were no measurements of kidney function, the level of plasma potassium concentration defined as hyperkalemia was not stated, and there were numerous other factors than hyperkalemia associated with reasons for hospitalization. Moreover, a more recent large study from Scotland with analysis over the same period of time also demonstrated an increased number of prescriptions for spironolactone after the RALES publication, but did not find any increase in hospitalizations associated with hyperkalemia [7].

The aim of the present study was to examine the safety of natriuretic doses of spironolactone (50-200 mg/day) on serum potassium concentration in New York Heart Association (NYHA) class III/IV HF patients over a prolonged outpatient follow-up.

\section{Methods}

A retrospective chart review study of medical records was undertaken of 18 patients with advanced HF on the heart transplant list of a single center who had received 50-200 mg/day of spironolactone over several weeks (see table 2). The study period included the time of listing for cardiac transplantation to the time of cardiac transplantation or left ventricular assist device placement. Increased doses of spironolactone were prescribed by attending cardiology physicians due to severe volume overload in spite of generous doses of loop diuretics. All patients from the pre-transplant database who were receiving increased doses of spironolactone (50-200 mg/day) for at least 1 week (see table 2) were included in the study; this numbered 18 patients with advanced HF. Spironolactone was the only MRA used in these patients. Serum sodium, potassium, chloride $(\mathrm{Cl}), \mathrm{CO}_{2}$, blood urea nitrogen (BUN) and serum creatinine were measured at baseline and 1 week after each increase in the spironolactone dose. Concomitant medications including potassium supplements were recorded. Loop diuretic doses were converted into furosemide equivalent doses ( $1 \mathrm{mg}$ of bumetanide $=20 \mathrm{mg}$ of torsemide $=40 \mathrm{mg}$ of furosemide). Due to the small number of patients, the MannWhitney U test was used to compare serum electrolytes levels.

All 18 patients eventually underwent cardiac transplantation and 4 had left ventricular assist device implantations as a bridge to transplant.

\section{Results}

Clinical and demographic characteristics of the 18 patients who were treated with increased doses of spironolactone (50-200 mg/day) are presented in table 1 . All patients had NYHA class III/IV symptoms with severe volume overload and were receiving high-dose loop diuretics (the average daily furosemide equivalent dose at baseline was $142.2 \pm 76.4 \mathrm{mg}$ ).

Spironolactone was titrated to $50 \mathrm{mg}$ in 6 patients, to $75 \mathrm{mg}$ in 4 patients, to $100 \mathrm{mg}$ in 6 patients and to more than $100 \mathrm{mg}$ in 2 patients. The duration of treatment is presented in table 2 . Fourteen of the 18 patients $(77.8 \%)$ received treatment until cardiac transplantation and the remaining 4 patients until left ventricular assist device implantation was performed 


\section{CardioRenal Medicine}

Table 1. Clinical and demographic characteristics of the HF patients at time of listing for cardiac transplantation

\begin{tabular}{l|l}
\hline Cardiorenal Med 2013;3:1-6 \\
\hline DOI: $\underline{10.1159 / 000346447}$ & $\begin{array}{l}\text { ○ 2013 S. Karger AG, Basel } \\
\text { www.karger.com/crm }\end{array}$ \\
\hline
\end{tabular}

Shchekochikhin et al.: Increased Spironolactone in Advanced Heart Failure: Effect of Doses Greater than $25 \mathrm{mg} /$ Day on Plasma Potassium Concentration

Number of patients
Age, years
Male gender, n (\%)
Caucasian ethnicity, n (\%)
Ischemic etiology of HF, n (\%)
Diabetes mellitus, n (\%)
Hypertension, n (\%)
Cerebrovascular disease, n (\%)
Permanent atrial fibrillation, $\mathrm{n}(\%)$
Cardiac output, l/min
Right atrial pressure, cm $\mathrm{H}_{2} \mathrm{O}$
Pulmonary artery wedge pressure, mm Hg
Left ventricular ejection fraction, \%
Left ventricular end-diastolic dimension, cm
Hemoglobin, mg/dl
ACE/ARB inhibitors, n (\%)
Beta-blockers, n (\%)
Digoxin, $\mathrm{n}(\%)$
Hydralazine, $\mathrm{n}(\%)$
Nitrates, $\mathrm{n}(\%)$
Statins, $\mathrm{n}(\%)$

$$
\begin{array}{r}
18 \\
46.4 \pm 12.1 \\
12(66.7) \\
12(67.7) \\
5(27.8) \\
2(11.1) \\
3(16.7) \\
4(22.2) \\
4(22.2) \\
3.52 \pm 1.40 \\
9.67 \pm 7.18 \\
19.17 \pm 7.75 \\
20.7 \pm 13.8 \\
7.37 \pm 1.81 \\
13.44 \pm 2.23 \\
15(83.3) \\
13(72.2) \\
16(88.9) \\
8(44.4) \\
10(55.6) \\
6(33.3)
\end{array}
$$

\begin{tabular}{|c|c|c|c|c|c|c|c|c|c|}
\hline Patient & $50 \mathrm{mg}$ & $75 \mathrm{mg}$ & $100 \mathrm{mg}$ & $125 \mathrm{mg}$ & $150 \mathrm{mg}$ & $175 \mathrm{mg}$ & $200 \mathrm{mg}$ & Total & Reason for withdrawal \\
\hline 1 & 1 & 6 & 8 & & & & & 15 & LVAD implantation \\
\hline 2 & 1 & 8 & & & & & & 9 & Cardiac transplantation \\
\hline $3(\mathrm{DM})$ & 4 & 12 & & & & & & 16 & Rise in creatinine \\
\hline 4 & 20 & 2 & 8 & & & & & 30 & Cardiac transplantation \\
\hline 5 & 1 & & 19 & & & & & 20 & Cardiac transplantation \\
\hline 6 & 160 & & 24 & 16 & 12 & 2 & 36 & 250 & LVAD implantation \\
\hline 7 & 1 & 2 & 12 & & & & & 15 & Cardiac transplantation \\
\hline 8 & 18 & 36 & & & & & & 54 & Cardiac transplantation \\
\hline 9 & 1 & 4 & & & & & & 5 & Cardiac transplantation \\
\hline 10 & 6 & & 24 & & & & & 30 & Cardiac transplantation \\
\hline 11 & 40 & & & & & & & 40 & Cardiac transplantation \\
\hline 12 & 16 & & & & & & & 16 & Cardiac transplantation \\
\hline 13 & 28 & & & & & & & 28 & Cardiac transplantation \\
\hline 14 & 1 & 1 & 12 & 4 & 6 & & 30 & 54 & Cardiac transplantation \\
\hline 15 & 1 & 4 & 2 & & & & & 7 & Cardiac transplantation \\
\hline 16 & 30 & & & & & & & 30 & Cardiac transplantation \\
\hline 17 (DM) & 72 & & & & & & & 72 & Rise in potassium \\
\hline 18 & 48 & & & & & & & 48 & Rise in creatinine \\
\hline
\end{tabular}

Table 2. Number of weeks on different doses of spironolactone

DM = Diabetes mellitus; LVAD = left ventricular assist device.

as a bridge to transplantation. In 3 patients treatment was withheld due to a rise in serum creatinine (from 1.8 to $2.1 \mathrm{mg} / \mathrm{dl}$ in the first patient, from 2.0 to $3.1 \mathrm{mg} / \mathrm{dl}$ in the second patient and from 1.8 to $2.2 \mathrm{mg} / \mathrm{dl}$ in the third patient). The latter patient was the only one in whom the plasma potassium concentration increased to 5.2 from $4.4 \mathrm{mEq} / \mathrm{l}$. Two of these 3 patients had diabetes mellitus. The mean duration of daily therapy of $50 \mathrm{mg}$ or more of spironolactone was 41 weeks. 
Shchekochikhin et al.: Increased Spironolactone in Advanced Heart Failure: Effect of Doses Greater than $25 \mathrm{mg} /$ Day on Plasma Potassium Concentration

Table 3. Serum electrolytes, BUN and serum creatinine at various doses of spironolactone

\begin{tabular}{crllllll}
\hline & $\mathrm{n}$ & $\begin{array}{l}\text { Sodium } \\
\mathrm{mEq} / \mathrm{l}\end{array}$ & $\begin{array}{l}\text { Potassium } \\
\mathrm{mEq} / \mathrm{l}\end{array}$ & $\begin{array}{l}\mathrm{CO}_{2} \\
\mathrm{mEq} / \mathrm{l}\end{array}$ & $\begin{array}{l}\mathrm{Cl} \\
\mathrm{mEq} / \mathrm{l}\end{array}$ & $\begin{array}{l}\mathrm{BUN} \\
\mathrm{mg} / \mathrm{dl}\end{array}$ & $\begin{array}{l}\text { Creatinine } \\
\mathrm{mg} / \mathrm{dl}\end{array}$ \\
\hline Baseline & 18 & $135.5 \pm 3.3$ & $4.0 \pm 0.5$ & $26.1 \pm 3.6$ & $98.7 \pm 4.2$ & $28.2 \pm 14.7$ & $1.3 \pm 0.5$ \\
$50 \mathrm{mg}$ & 16 & $135.3 \pm 3.0$ & $4.0 \pm 0.5$ & $26.3 \pm 2.1$ & $99.3 \pm 4.2$ & $25.3 \pm 15.9$ & $1.2 \pm 0.4$ \\
$75 \mathrm{mg}$ & 9 & $132.7 \pm 2.3$ & $3.9 \pm 0.6$ & $24.8 \pm 2.4$ & $96.1 \pm 3.9$ & $29.6 \pm 13.4$ & $1.5 \pm 0.5$ \\
$100 \mathrm{mg}$ & 8 & $134.8 \pm 3.0$ & $4.0 \pm 0.3$ & $23.9 \pm 2.1$ & $100.6 \pm 1.6$ & $27.1 \pm 14.4$ & $1.4 \pm 0.5$ \\
$125 \mathrm{mg}$ & 2 & $134.0 \pm 5.7$ & $4.3 \pm 0.1$ & $26.0 \pm 1.4$ & $98.5 \pm 4.9$ & $15.0 \pm 4.2$ & $1.0 \pm 0.4$ \\
$150 \mathrm{mg}$ & 1 & 140 & 3.7 & 25.0 & 102 & 9 & 0.7 \\
$200 \mathrm{mg}$ & 2 & $135.5 \pm 3.5$ & $4.2 \pm 0.3$ & $25.5 \pm 4.9$ & $99.0 \pm 4.2$ & $14.5 \pm 0.7$ & $1.0 \pm 0.3$ \\
\hline
\end{tabular}

Table 4. Potassium supplements and furosemide equivalent doses

\begin{tabular}{crcc}
\hline & $\mathrm{n}$ & $\begin{array}{l}\text { Median potassium } \\
\mathrm{mEq} / \text { day }\end{array}$ & $\begin{array}{l}\text { Furosemide } \\
\mathrm{mg} / \text { day }\end{array}$ \\
\hline Baseline & 18 & 40 & $146.7 \pm 79.7$ \\
$50 \mathrm{mg}$ & 16 & 30 & $133.8 \pm 81.6$ \\
$75 \mathrm{mg}$ & 9 & 40 & $144.4 \pm 102.8$ \\
$100 \mathrm{mg}$ & 8 & 60 & $195.0 \pm 114.0$ \\
$125 \mathrm{mg}$ & 2 & 130 & 240 \\
$150 \mathrm{mg}$ & 1 & 80 & 360 \\
$200 \mathrm{mg}$ & 2 & 120 & $300 \pm 84.9$ \\
\hline
\end{tabular}

Serum electrolytes, BUN and serum creatinine were measured at baseline and after every increase in the spironolactone dose (table 3). Serum potassium did not increase significantly from baseline to the last follow-up measurement ( $4.0 \pm 0.5$ vs. $4.2 \pm 0.5, p>$ $0.05)$. However, a modest decrease in serum sodium was observed (135.5 \pm 3.3 vs. $133.6 \pm$ $2.6, \mathrm{p}=0.016)$. Other serum electrolytes, BUN and serum creatinine were not significantly different from baseline $\left(26.1 \pm 3.6\right.$ vs. $26.1 \pm 3.2 \mathrm{mEq} / \mathrm{l}$ for total $\mathrm{CO}_{2}, 98.7 \pm 4.2$ vs. $95.6 \pm$ $8.4 \mathrm{mEq} / \mathrm{l}$ for $\mathrm{Cl}, 28.2 \pm 14.7 \mathrm{vs} .31 .0 \pm 13.2 \mathrm{mg} / \mathrm{dl}$ for BUN, and $1.3 \pm 0.5 \mathrm{vs} .1 .4 \pm 0.5 \mathrm{mg} / \mathrm{dl}$ for creatinine, $p>0.05$ for all). Potassium supplements and diuretic doses are presented in table 4 .

\section{Discussion}

Our retrospective study demonstrates that fluid-overloaded patients with advanced HF can safely receive increased doses of MRA. In our 18 patients followed for a mean duration of 41 weeks after listing for cardiac transplantation, only 3 required withdrawal of MRA and in only 1 did that include modest hyperkalemia. These patients were relatively young and had only modest increments in serum creatinine. Thus, 17 of $18 \mathrm{HF}$ patients tolerated natriuretic doses of spironolactone without an increase in serum potassium concentration. Overall, there were 738 total patient-weeks for all patients on $\geq 50 \mathrm{mg} /$ day of spironolactone with a mean change in serum potassium concentration from 4.0 to $4.2 \mathrm{mEq} / \mathrm{l}$. In the current study, $83 \%$ of the patients were receiving renin-angiotensin-aldosterone system inhibitors and $72 \%$ were receiving beta-blockers, both of which can increase plasma potassium. In addition to improving the urinary potassium-losing effect of loop diuretics, perhaps aldosterone breakthrough was involved in the absence of any effect on plasma potassium [8]. 
Congestion is a major cause of symptoms and a predictor of mortality in HF patients. Thus, loop diuretics are prescribed as the cornerstone of HF treatment. Nevertheless, on discharge, $50 \%$ of these HF patients have continued symptoms of congestion including dyspnea, and approximately $20 \%$ of these patients have gained weight in spite of intravenous loop diuretic therapy [9]. It also has been estimated that $20 \%$ of these patients are loop diuretic resistant. Natriuretic doses of MRA should be expected to at least improve the symptoms of congestion but might also improve prognosis. While 'loop diuretic resistance' has not been well defined, it is clear that loop diuretic therapy alone has not been adequate in treating the congestion of HF. Secondary hyperaldosteronism is not only a pivotal pathogenic factor in HF [10], but can play an important role in loop diuretic resistance [11]. Moreover, loop diuretics block sodium $\mathrm{Cl}$ transport at the macula densa, an effect that further stimulates the renin-angiotensin-aldosterone system. A rapid natriuresis in response to loop diuretics may also exceed the rate of fluid mobilization from the interstitium and worsen renal function even while the deleterious effects of fluid overload and congestion persist. In contrast to loop diuretics, the natriuretic effect of MRA occurs in the more distal collecting duct where approximately $4 \%$ of filtered sodium is reabsorbed. Therefore, the natriuresis is slower than with loop diuretics and thus may not exceed the rate of mobilization of interstitial fluid. This is one reason why MRA are considered safe and effective to begin treatment for edema and ascites in cirrhotic patients [12]. Diuretic resistance in cirrhotic patients has been defined by the International Ascites Club as failure to respond to daily spironolactone doses of $400 \mathrm{mg}$ and furosemide of $160 \mathrm{mg}$ [12]. Thus, in spite of the common pathophysiology of $\mathrm{HF}$ and cirrhosis [11], the standard dose of spironolactone is $25 \mathrm{mg} /$ day in HF patients.

There are potential reasons for this situation. First, aldosterone may not be involved in the sodium retention in HF; alternatively, aldosterone production may be adequately blocked by ACE inhibitors or ARB. There is, however, evidence to incriminate the sodium-retaining effect of aldosterone in advanced HF. Several small studies demonstrated reversal of sodium retention in advanced HF with spironolactone doses of 100-400 mg/day. In 1965, Braunwald et al. [13] demonstrated that patients with HF have a markedly reduced rate of renal sodium excretion in response to an oral sodium load and that cumulative sodium retention was closely correlated with an increase in body weight. Although the study was not designed to determine the mechanism of sodium retention, 3 patients were given $100 \mathrm{mg}$ of spironolactone daily. In these 3 patients, urinary sodium excretion increased substantially, thus supporting the hypothesis that secondary hyperaldosteronism plays an important role in the sodium and water retention in HF. In a subsequent study from the University of Colorado reversal of sodium retention in advanced $\mathrm{HF}$ was demonstrated with a spironolactone dose of $200 \mathrm{mg}$ twice daily [14]. This was associated with a rather small increase in serum potassium from 3.86 to $4.10 \mathrm{mEq} / \mathrm{l}$. In another study in HF patients on moderate doses of ACE inhibitors who were considered to be diuretic resistant, a $100-\mathrm{mg} /$ day dose of spironolactone was found to be natriuretic, with an increase in serum potassium from 4.0 to $4.3 \mathrm{mmol} / \mathrm{l}$ within 7 days [15].

A potential limitation of the current study is that these HF patients were selected from the cardiac transplant list. Increased doses of spironolactone were prescribed due to clinical judgment of fluid overload and loop diuretic resistance. Since the patients were selected for heart transplant, they did not have advanced renal impairment. Thus, the results of the study cannot be generalized to the entire HF patients' population. For example, HF patients who are not healthy enough to be placed on the heart transplant list or have more advanced renal impairment may be more prone to develop hyperkalemia with increased MRA doses.

In conclusion, the present study indicates that increased doses of MRA can be used in selected patients with advanced HF without the development of hyperkalemia. Even so, the cessation of potassium supplements and a low-potassium diet would further decrease any 


\section{CardioRenal Medicine}

\begin{tabular}{l|l}
\hline \multicolumn{2}{l|}{ Cardiorenal Med 2013;3:1-6 } \\
\hline DOI: $10.1159 / 000346447$ & $\begin{array}{l}\text { (c) 2013 S. Karger AG, Basel } \\
\text { www.karger.com/crm }\end{array}$ \\
\hline
\end{tabular}

Shchekochikhin et al.: Increased Spironolactone in Advanced Heart Failure: Effect of Doses Greater than 25 mg/Day on Plasma Potassium Concentration

risk of hyperkalemia in these HF patients. This may be particularly true in HF patients with diabetes mellitus. Controlled studies, addressing increased MRA doses in fluid-overloaded HF patients are needed to assess efficacy and safety.

\section{Acknowledgements}

Dr. D. Shchekochikhin's cardiorenal fellowship has been sponsored by Russian President's Scholarship for Studying Abroad and Gambro UF Solutions, Inc.

\section{References}

1 Pitt B, Zannad F, Remme WJ, et al; Randomized Aldactone Evaluation Study Investigators: The effect of spironolactone on morbidity and mortality in patients with severe heart failure. N Engl J Med 1999;341:709717.

2 Pitt B, Remme W, Zannad F, Neaton J, Martinez F, Roniker B, Bittman R, Hurley S, Kleiman J, Gatlin M; Eplerenone Post-Acute Myocardial Infarction Heart Failure Efficacy and Survival Study Investigators: Eplerenone, a selective aldosterone blocker, in patients with left ventricular dysfunction after myocardial infarction. $\mathrm{N}$ Engl J Med 2003;348:1309-1321.

3 Zannad F, McMurray JJ, Krum H, van Veldhuisen DJ, Swedberg K, Shi H, Vincent J, Pocock SJ, Pitt B; EMPHASISHF Study Group: Eplerenone in patients with systolic heart failure and mild symptoms. N Engl J Med 2011; 364:11-21.

4 The RALES Investigators: Effectiveness of spironolactone added to an angiotensin-converting enzyme inhibitor and a loop diuretic for severe chronic congestive heart failure (The Randomized Aldactone Evaluation Study [RALES]). Am J Cardiol 1996;78:902-907.

5 Testani JM, Chen J, McCauley BD, Kimmel SE, Shannon RP: Potential effects of aggressive decongestion during the treatment of decompensated heart failure on renal function and survival. Circulation 2010;122:265-272.

6 Juurlink D, Mamdani M, Lee DS, et al: Rates of hyperkalemia after publication of the Randomized Aldactone Evaluation Study. N Engl J Med 2004;351:543-551.

7 Li W, Struthers AD, Fahey T, Watson AD, MacDonald TM: Spironolactone use and renal toxicity: population based longitudinal analysis. BMJ 2010;340:c1768.

- 8 Schrier RW: Aldosterone 'escape' versus 'breakthrough'. Nat Rev Nephrol 2010;6:61.

- 9 Jencks SF, Williams MV, Coleman EA: Rehospitalizations among patients in the Medicare fee-for-service program. N Engl J Med 2009;360:1418-1428.

10 Schrier RW: Decreased effective blood volume in edematous disorders: what does this mean? J Am Soc Nephrol 2007;18:2028-2031.

11 Bansal S, Lindenfeld JA, Schrier RW: Sodium retention in heart failure and cirrhosis: potential role of natriuretic doses of mineralocorticoid antagonist? Circ Heart Fail 2009;2:370-376.

12 Ginès P, Schrier RW: Renal failure in cirrhosis. N Engl J Med 2009;361:1279-1290.

13 Braunwald E, Plauth HW Jr, Morrow AG: A method for the detection and quantification of impaired sodium excretion. Circulation 1965;32:223-231.

14 Hensen J, Abraham WT, Dürr JA, Schrier RW: Aldosterone in congestive heart failure: analysis of determinants and role in sodium retention. Am J Nephrol 1991;11:441-446.

15 Van Vliet AA, Donker AJ, Nauta JJ, et al: Spironolactone in congestive heart failure refractory to high-dose loop diuretic and low-dose angiotensin-converting enzyme inhibitor. Am J Cardiol 1993;71:21A-28A. 